\title{
Cycloheximide congeners produced by Streptomyces sp. SC0581 and photoinduced interconversion between $(E)$ - and (Z)-2,3-dehydroanhydrocycloheximides
}

\author{
Li Yang ${ }^{1,2}$, Ping Wu ${ }^{1}$, Jinghua Xue ${ }^{1}$, Huitong Tan ${ }^{1}$, Zheng Zhang ${ }^{1}$ and Xiaoyi Wei ${ }^{* 1}$
}

Open Access

\author{
Full Research Paper \\ Address: \\ ${ }^{1}$ Key Laboratory of Plant Resources Conservation and Sustainable \\ Utilization, Guangdong Provincial Key Laboratory of Digital Botanical \\ Garden, South China Botanical Garden, Chinese Academy of \\ Sciences, Xingke Road 723, Tianhe District, Guangzhou 510650, \\ China and ${ }^{2}$ University of Chinese Academy of Sciences, Yuquanlu \\ 19A, Beijing 100049, China \\ Email: \\ Xiaoyi Wei ${ }^{*}$ - wxy@scbg.ac.cn \\ * Corresponding author

\section{Keywords:} \\ antifungal activity; cycloheximide derivatives; E/Z photoisomerization; \\ Streptomyces sp; theoretical conformational analysis
}

Beilstein J. Org. Chem. 2017, 13, 1039-1049. doi:10.3762/bjoc. 13.103

Received: 03 March 2017

Accepted: 10 May 2017

Published: 30 May 2017

Associate Editor: C. Stephenson

(C) 2017 Yang et al.; licensee Beilstein-Institut. License and terms: see end of document.

\begin{abstract}
Three new cycloheximide congeners, 2,3-dehydro- $\alpha$-epi-isocycloheximide (1), (E)- and (Z)-2,3-dehydroanhydrocycloheximides (2 and 3), together with three known compounds, anhydroisoheximide (4), cycloheximide (5), and isocycloheximide (6), were obtained from the cultures of Streptomyces sp. SC0581. Their structures were elucidated by extensive spectroscopic analysis in combination with theoretical conformational analysis and ECD computations. The photoinduced interconversion between $\mathbf{2}$ and $\mathbf{3}$ was observed and verified and the possible reaction path and mechanism were proposed by theoretical computations. The antifungal and cytotoxic activities of 1-6 were evaluated and suggested that 2,3-dehydrogenation results in the loss of the activities and supported that the $\mathrm{OH}-\alpha$ is important to the activities of cycloheximide congeners.
\end{abstract}

\section{Introduction}

The glutarimide-containing antibiotics represent a fascinating class of natural products that exhibit a multitude of biological activities. The most famous representative of this family, cycloheximide (5), has been used for decades as an inhibitor of eukaryotic translation elongation [1-3]. Other members of this family show potent cell migration inhibition and antiviral activity [4-6], which continues to capture the attention from researchers in synthetic and biosynthetic chemistry, medicinal chemistry, and pharmacology. However, cycloheximide (5) has held back the clinical and agricultural applications due to its reproductive toxicity [7]. Identifying new analogues that offer similar activity without the toxic side-effects could provide a viable lead of therapeutic drugs or agricultural pesticides. During the course of our searching for bioactive microbial metabolites [8,9], a culture extract of Streptomyces sp. SC0581 was found to show antifungal activity against the 
phytopathogen Phytophthora infestans. Bioassay-guided fractionation of the extract led to the isolation of three new cycloheximide congeners (Figure 1), 2,3-dehydro- $\alpha$-epi-isocycloheximide (1), $(E)$ - and (Z)-2,3-dehydroanhydrocycloheximides ( 2 and $\mathbf{3}$ ), and one known but new naturally occurring cycloheximide congener, anhydroisoheximide (4) [6], together with cycloheximide (5) and isocycloheximide (6) [10]. Their structures were elucidated by spectroscopic analysis, theoretical conformational analysis, and ECD/TDDFT calculations. The photoinduced interconversion between $\mathbf{2}$ and $\mathbf{3}$ was observed and verified, and the possible reaction path and mechanism were proposed by theoretical computations. All the isolated compounds were evaluated for antifungal activity and cancer cell toxicity. Herein are reported the isolation, structural elucidation, and biological activities of these compounds and the interconversion between $\mathbf{2}$ and $\mathbf{3}$.<smiles>[Z]C1=C[C@@H](C)C[C@H]([C@H](O)CC2CC(=O)N[C+](C)C2)C1=O</smiles><smiles>CC1=CC(C)CC(=CCC2CC(=O)NC(=O)C2)C1=O</smiles>

2<smiles>CC1=C[C@H](C)C/C(=C/CC2CC(=O)NC(=O)C2)C1=O</smiles>

3<smiles>CC=C1CC(C)C=C(C)C1=O</smiles><smiles>CC=C1CC(C)C=C(C)C1=O</smiles><smiles>CC=C1C[C@H](C)C[C@H](C)C1=O</smiles>

Figure 1: Structures of 1-6 and 2a-4a.

\section{Results and Discussion \\ Structure elucidation}

The molecular formula of compound $\mathbf{1}$ was established as $\mathrm{C}_{15} \mathrm{H}_{21} \mathrm{NO}_{4}$ based on the HRESI(+)-MS ion at $\mathrm{m} / z 302.1357$ $[\mathrm{M}+\mathrm{Na}]^{+}$(calcd 302.1363). Its ${ }^{1} \mathrm{H}$ and ${ }^{13} \mathrm{C}$ NMR spectral data (Table 1), in combination with the HSQC spectrum, indicated the presence of a conjugated keto carbonyl $\left(\delta_{\mathrm{C}} 202.6\right)$, two amide carbonyls $\left(\delta_{\mathrm{C}} 175.5,175.7\right)$, a trisubstituted olefin
$\left(\delta_{\mathrm{H}} 6.65 ; \delta_{\mathrm{C}} 134.2,151.9\right)$, two methyls $\left(\delta_{\mathrm{H}} 1.72,1.16 ; \delta_{\mathrm{C}} 14.5\right.$, 20.3), four aliphatic methines with one being oxygenated $\left(\delta_{\mathrm{H}} 4.26 ; \delta_{\mathrm{C}} 67.3\right)$, and four methylenes. Analysis of the ${ }^{1} \mathrm{H},{ }^{1} \mathrm{H}-\mathrm{COSY}$ and $\mathrm{HMBC}$ spectra, in particular the HMBC correlations from the olefinic methyl protons $\left(\delta_{\mathrm{H}} 1.72, \mathrm{H}_{3}-7\right)$ to $\mathrm{C} 1\left(\delta_{\mathrm{C}} 202.6\right), \mathrm{C} 2\left(\delta_{\mathrm{C}} 134.2\right)$, and $\mathrm{C} 3\left(\delta_{\mathrm{C}} 151.9\right)$, from the aliphatic methyl $\left(\delta_{\mathrm{H}} 1.16, \mathrm{H}_{3}-8\right)$ to $\mathrm{C} 3, \mathrm{C} 4\left(\delta_{\mathrm{C}} 31.8\right)$, and $\mathrm{C} 5$ $\left(\delta_{\mathrm{C}} 31.7\right)$, and from the oxymethine $\left(\delta_{\mathrm{H}} 4.26, \mathrm{H}-\alpha\right)$ to $\mathrm{C} 1$ and C6 $\left(\delta_{\mathrm{C}} 52.2\right)$, readily constructed a planar structure of 2,3-dehydrocycloheximide.

The relative configuration of the cyclohexenone ring in $\mathbf{1}$ was assigned by analysis of the ${ }^{1} \mathrm{H}$ NMR proton coupling constants (Table 1) and NOESY correlations. The large proton coupling constants, $J_{\mathrm{H} 6 / \mathrm{H} 5 \mathrm{ax}}=14.4 \mathrm{~Hz}$ and $J_{\mathrm{H} 5 \mathrm{ax} / \mathrm{H} 4}=11.3 \mathrm{~Hz}$, suggested that $\mathrm{H} 6$ and $\mathrm{H} 4$ were in pseudo-axial positions and on the same face of the cyclohexenone ring. This was further corroborated by the presence of strong NOE correlations of $\mathrm{H}_{3}-8$ with both $\mathrm{H} 5 \mathrm{ax}$ and $\mathrm{H} 5 \mathrm{eq}$ and of $\mathrm{H} 5 \mathrm{eq}$ with both $\mathrm{H} 6$ and $\mathrm{H} 4$ in the NOESY spectrum (Figure 2). It was also in agreement with no NOE correlation being detected between H5ax and $\mathrm{H} 6$ or H4. However, straightforward analysis of the ${ }^{1} \mathrm{H}$ NMR and NOESY spectra was unable to assign the relative configuration of $\mathrm{C} \alpha$ due to its location on the flexible side chain. In order to clarify the relative configuration of this chiral carbon, theoretical conformational analysis was carried out on two possible stereoisomers, $(4 R, 6 R, \alpha S)-\mathbf{1}$ and $(4 R, 6 R, \alpha R)-\mathbf{1}$. MMFF conformational search and subsequent geometry optimization using the DFT-D3 method at the B3LYP-D3/6-31G(d) level followed by a higher level of energy calculations at the B3LYP-D3/def2-TZVP level afforded 14 and 11 distinctive low-energy conformers $(\Delta G<2.5 \mathrm{kcal} / \mathrm{mol})$ for $(4 R, 6 R, \alpha S)-\mathbf{1}$ and $(4 R, 6 R, \alpha R)-\mathbf{1}$, respectively (Table $\mathrm{S} 1$, Supporting Information File 1). Among the low-energy conformers of $(4 R, 6 R, \alpha S)$ 1, those having a gauche relationship between $\mathrm{H}-\alpha / \mathrm{H}-6$ were found to be greatly dominant (accounting for about 96\%) in the equilibrium mixture in $\mathrm{MeOH}$, which could be categorized into two groups, $(S)$-1a and $(S)$-1b, based on the torsion angle of H6-C6-C $\alpha-\mathrm{H} \alpha\left(\Phi_{\mathrm{H} 6 / \mathrm{H} \alpha}\right)$ being around either $-62^{\circ}$ or $+55^{\circ}$ and each group constituted about $48 \%$ equilibrium populations. As can be seen in Figure 2, conformers in both $(S)$-1a and $(S)$-1 b groups, represented by the second lowest energy minimum $(S)-\mathbf{1 a 1}(\Delta G=0.02 \mathrm{kcal} / \mathrm{mol})$ and the global energy minimum $(S)$-1b1, respectively, matched up well with the proton coupling constant between $\mathrm{H} 6 / \mathrm{H} \alpha(J=4.3 \mathrm{~Hz})$ and the aforementioned NOESY correlations. Furthermore, conformers in group (S)-1a were also consistent with the diagnostic NOE interaction of $\mathrm{H} \alpha / \mathrm{H} 5$ eq observed in the NOESY spectrum. In turn, $(4 R, 6 R, \alpha R)-1$ afforded the dominant conformers (accounting for about $82 \%$ equilibrium populations), as represented by the global energy minimum $(R)$-1a1 (Figure 2), having an anti rela- 


\begin{tabular}{|c|c|c|c|c|c|c|}
\hline \multirow[b]{2}{*}{ position } & \multicolumn{2}{|r|}{1} & \multicolumn{2}{|r|}{2} & \multicolumn{2}{|r|}{3} \\
\hline & $\delta_{C}$, type & $\delta_{H}(J$ in $\mathrm{Hz})$ & $\delta_{C}$, type & $\delta_{\mathrm{H}}(\mathrm{J}$ in $\mathrm{Hz})$ & $\delta_{C}$, type & $\delta_{H}(J$ in $\mathrm{Hz})$ \\
\hline 1 & 202.6, C & & $190.5, \mathrm{C}$ & & 192.8, C & \\
\hline 2 & 134.2, C & & 136.2, C & & 137.5, C & \\
\hline 3 & $151.9, \mathrm{CH}$ & $6.65 \mathrm{dq}(3.7,1.5)$ & $153.4, \mathrm{CH}$ & $6.79 \mathrm{dq}(3.6,1.3)$ & $152.3, \mathrm{CH}$ & $6.71 \mathrm{dq}(3.2,1.3)$ \\
\hline 4 & $31.8, \mathrm{CH}$ & $2.59 \mathrm{~m}$ & $32.3, \mathrm{CH}$ & $2.59 \mathrm{~m}$ & $32.2, \mathrm{CH}$ & $2.27 \mathrm{~m}$ \\
\hline 5 & $31.7, \mathrm{CH}_{2}$ & $\begin{array}{l}\text { eq } 2.16 \mathrm{dtd}(12.7,4.3,1.8) \\
\text { ax } 1.39 \mathrm{ddd}(14.4,12.7,11.3)\end{array}$ & $34.6, \mathrm{CH}_{2}$ & $\begin{array}{l}\beta 2.86 \mathrm{dd}(14.3,5.1) \\
\alpha 2.30 \mathrm{~m}\end{array}$ & 43.3, $\mathrm{CH}_{2}$ & $\begin{array}{l}\beta 2.74 \mathrm{dd}(13.4,5.1) \\
\alpha 2.34 \mathrm{~m}\end{array}$ \\
\hline 6 & $52.2, \mathrm{CH}$ & $2.54 \mathrm{dt}(14.4,4.3)$ & 136.1, C & & 136.2, C & \\
\hline 7 & $14.5, \mathrm{CH}_{3}$ & $1.72 \mathrm{dd}(2.4,1.4)$ & $16.4, \mathrm{CH}_{3}$ & $1.80 \mathrm{t}(1.6)$ & $16.1, \mathrm{CH}_{3}$ & $1.76 \mathrm{t}(1.6)$ \\
\hline 8 & $20.3, \mathrm{CH}_{3}$ & $1.16 \mathrm{~d}(7.2)$ & $21.0, \mathrm{CH}_{3}$ & $1.14 \mathrm{~d}(7.9)$ & $20.5, \mathrm{CH}_{3}$ & $1.13 \mathrm{~d}(7.2)$ \\
\hline$\alpha$ & $67.3, \mathrm{CH}$ & 4.26 ddd $(10.4,4.3,2.1)$ & 134.6, CH & $6.59 \mathrm{tt}(7.6,1.7)$ & $137.1, \mathrm{CH}$ & $5.86 \mathrm{tt}(7.7,1.4)$ \\
\hline$\beta$ & $37.2, \mathrm{CH}_{2}$ & $\begin{array}{l}1.58 \mathrm{ddd}(14.0,10.4,3.6) \\
1.33 \mathrm{ddd}(14.0,8.2,2.1)\end{array}$ & $33.4, \mathrm{CH}_{2}$ & $2.31-2.42 \mathrm{~m}$ & $34.5, \mathrm{CH}_{2}$ & $2.56 \mathrm{~m}$ \\
\hline $2^{\prime}$ & 175.7, C & & 175.2, C & & $175.4, \mathrm{C}$ & \\
\hline $3^{\prime}$ & $38.0, \mathrm{CH}_{2}$ & $\begin{array}{l}2.69 \mathrm{~m} \\
2.39 \mathrm{~m}\end{array}$ & $38.1, \mathrm{CH}_{2}$ & $\begin{array}{l}2.67 \mathrm{~m} \\
2.31-2.42 \mathrm{~m}\end{array}$ & 38.2, $\mathrm{CH}_{2}$ & $\begin{array}{l}2.60-2.66 \mathrm{~m} \\
2.31-2.42 \mathrm{~m}\end{array}$ \\
\hline $4^{\prime}$ & $27.4, \mathrm{CH}$ & $2.36 \mathrm{~m}$ & $31.6, \mathrm{CH}$ & $2.31-2.42 \mathrm{~m}$ & $33.8, \mathrm{CH}$ & $2.60-2.66 \mathrm{~m}$ \\
\hline $5^{\prime}$ & $36.5, \mathrm{CH}_{2}$ & $\begin{array}{l}2.79 \mathrm{~m} \\
2.37 \mathrm{~m}\end{array}$ & $38.2, \mathrm{CH}_{2}$ & $\begin{array}{l}2.60-2.66 \mathrm{~m} \\
2.31-2.42 \mathrm{~m}\end{array}$ & $38.3, \mathrm{CH}_{2}$ & $\begin{array}{l}2.60-2.66 \mathrm{~m} \\
2.31-2.42 \mathrm{~m}\end{array}$ \\
\hline $6^{\prime}$ & $175.5, \mathrm{C}$ & & 175.2, C & & $175.4, \mathrm{C}$ & \\
\hline
\end{tabular}

tionship $\left(\Phi_{\mathrm{H} 6 / \mathrm{H} \alpha} \approx 174^{\circ}\right)$ between $\mathrm{H} \alpha / \mathrm{H} 6$, which were inconsistent with the small $J_{\mathrm{H} 6 / \mathrm{H} \alpha}$ value $(4.3 \mathrm{~Hz})$ and the absence of an NOE correlation between $\mathrm{H} \alpha / \mathrm{H} 5 \mathrm{ax}$ in the experimental spectra. Accordingly, the relative configuration of $\mathbf{1}$ was assigned to be $4 R^{*}, 6 R^{*}, \alpha S^{*}$. In order to determine the absolute configuration, the low-energy conformers of both stereoisomers were subjected to TDDFT calculations of the electronic circular dichroism (ECD) spectra. As shown in Figure 3, the calculated ECD spectra of $(4 R, 6 R, \alpha S)-1$ and $(4 R, 6 R, \alpha R)-1$ were similar to one another and both in good agreement with the measured spectrum of 1 , which indicated a $R$ configuration of both $\mathrm{C} 4$ and $\mathrm{C} 6$ but gave no evidence for any of $\mathrm{C} \alpha$. For the latter, the $S$ configuration was assigned according to the relative configuration as deduced from above conformational analysis. Therefore, compound 1 was defined as 2,3-dehydro- $\alpha$-epi-isocycloheximide.

Compounds $\mathbf{2}$ and $\mathbf{3}$ were obtained as a 7:3 equilibrium mixture. They could be separated by reverse phase HPLC using aqueous $\mathrm{MeOH}$, but readily inter-converted and reached equilibrium in a couple of days at room temperature (in $\mathrm{MeOH}$ ). The mixture gave a $[\mathrm{M}+\mathrm{Na}]^{+}$ion peak at $m / z 284.1255$ in the HRESI(+)MS, appropriate for a molecular formula of $\mathrm{C}_{15} \mathrm{H}_{19} \mathrm{NO}_{3}$, having one $\mathrm{H}_{2} \mathrm{O}$ unit less than that of 1 . The 1D NMR spectra of the mixture contained two sets of signals in the ratio of 7:3 (according to the ${ }^{1} \mathrm{H}$ NMR proton integral values), corresponding to two isomeric molecules $\mathbf{2}$ and $\mathbf{3}$ (Table 1), respectively. Each set of proton and carbon signals resembled those of compound $\mathbf{1}$ except for replacement of the resonances for the hydroxymethine at $\mathrm{C} \alpha$ and the aliphatic methine at $\mathrm{C} 6$ in $\mathbf{1}$ by the signals for an additional trisubstituted olefin $\left[\delta_{\mathrm{H}} 6.59 ; \delta_{\mathrm{C}} 134.6(\mathrm{CH})\right.$, $136.1(\mathrm{C})$ in 2 and $\delta_{\mathrm{H}} 5.86 ; \delta_{\mathrm{C}} 137.1(\mathrm{CH}), 136.2(\mathrm{C})$ in 3 ], suggesting a gross structure of an anhydrous derivative of $\mathbf{1}$. This was supported by the HMBC correlations of the olefinic proton $\mathrm{H} \alpha$ with $\mathrm{C} 1\left(\delta_{\mathrm{C}} 190.5\right.$ in $2,192.8$ in $\left.\mathbf{3}\right), \mathrm{C} 4$ ' $\left(\delta_{\mathrm{C}} 31.6\right.$ in $\mathbf{2}$, 33.8 in $\mathbf{3})$, and $\mathrm{C} 5\left(\mathbf{2}, \delta_{\mathrm{C}} 34.6\right.$ in $\mathbf{2}, 43.3$ in $\left.\mathbf{3}\right)$. The structural difference between $\mathbf{2}$ and $\mathbf{3}$ was identified in the NOESY spectrum. The presence of a strong NOE correlation between the minor $\mathrm{H} \alpha\left(\delta_{\mathrm{H}} 5.86\right)$ and $\mathrm{H} 5 \beta\left(\delta_{\mathrm{H}} 2.74\right)$ was observed while the same correlation between the major counterparts $\left[\delta_{\mathrm{H}} 6.59(\mathrm{H} \alpha)\right.$, $2.86(\mathrm{H} 5 \beta)$ ] could not be found in the spectrum, revealing the geometrical configurations of the double bond between $\mathrm{C} 6 / \mathrm{C} \alpha$ were $E$ in $\mathbf{2}$ and $Z$ in $\mathbf{3}$. In order to assign their absolute configurations, $(R)-2$ and $(R)-3$ were separately subjected to ECD/ TDDFT calculations. As can be seen in Figure 4, the calculated ECD curve of $(R)$-2 agreed well with the experimental spectrum of the mixture, whereas, that of $(R)-\mathbf{3}$ was largely inconsistent with the measured spectrum. Nevertheless, the summed ECD spectrum of $(R)-2$ and $(R)-3$ (7:3) showed the best fit with the experimental spectrum, indicating the $R$ configuration of $\mathrm{C} 4$ in both compounds. Therefore, the structures of $\mathbf{2}$ and $\mathbf{3}$ were elucidated as (E)- and (Z)-2,3-dehydroanhydrocycloheximides, respectively. It is noted that a compound of unspecified absolute configuration was recently reported to possess the same planar structure as $\mathbf{3}$ [11]. 

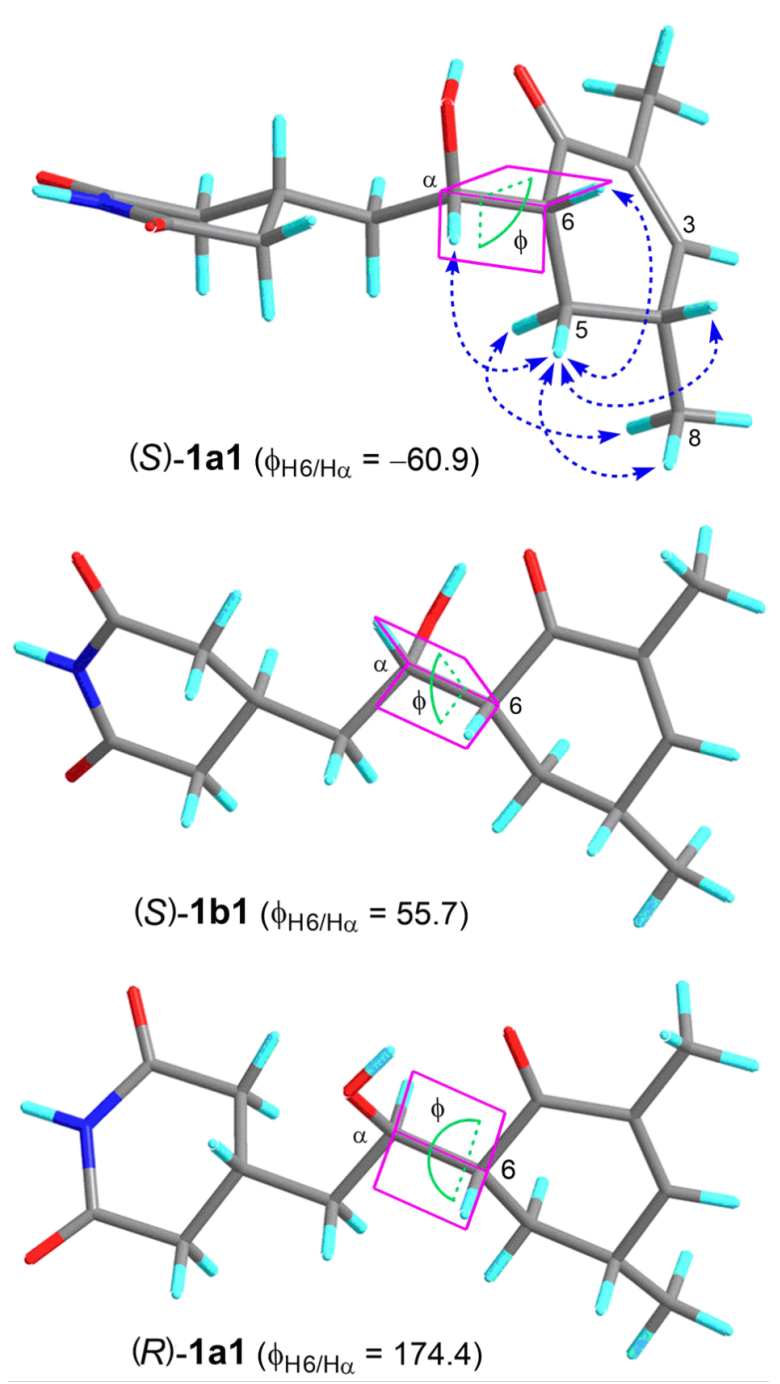

Figure 2: Representatives of the theoretical dominant conformers of $(4 R, 6 R, \alpha S)-1((S)-1 \mathbf{a} 1$ and $(S)-1 \mathrm{~b} 1)$ and $(4 R, 6 R, \alpha R)-1((R)-1 \mathbf{a} 1)$ in equilibrium populations (in $\mathrm{MeOH}$ ) and key NOESY correlations (dashed arrows) of 1.

\section{Photoinduced interconversion between 2 \\ and 3}

When elucidating the structures of $\mathbf{2}$ and $\mathbf{3}$, we understood that the interconversion between $\mathbf{2}$ and $\mathbf{3}$ is likely a photochemical process as it is known that most $Z / E$ isomerizations of carbon double bonds in conjugated olefins and $\alpha, \beta$-enones are facilitated by this process [12-14]. However, as all experiments in the present study were carried out either in the dark (fermentation) or under indoor light (extraction and fractionation), with neither direct sunlight shining into nor any artificial high-energy light being applied in the laboratory, we doubted if the fast conversion was induced by our laboratory indoor light. Thus, compounds $\mathbf{2}$ and $\mathbf{3}$ in the mixture were separated by preparative HPLC and their MeOH solutions were exposed to the natural indoor light at room temperature and subjected to UPLC analy-

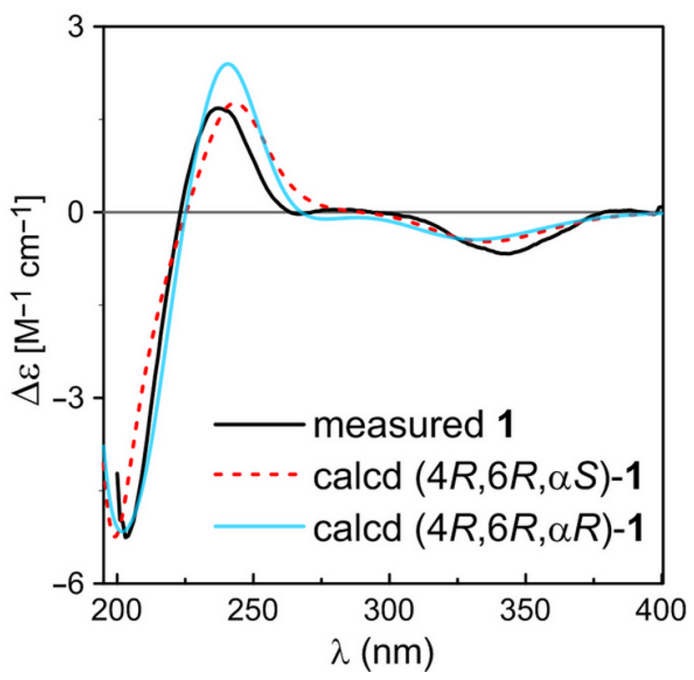

Figure 3: Comparison of the experimental ECD spectrum of 1 with the M11/TZVP calculated spectra of $(4 R, 6 R, \alpha S)-1$ and $(4 R, 6 R, \alpha R)-1$ in $\mathrm{MeOH}(\sigma=0.38 \mathrm{eV}$ for both; shift $=+15$ and $+10 \mathrm{~nm}$, scaling factor $=0.50$ and 1.0 , respectively).

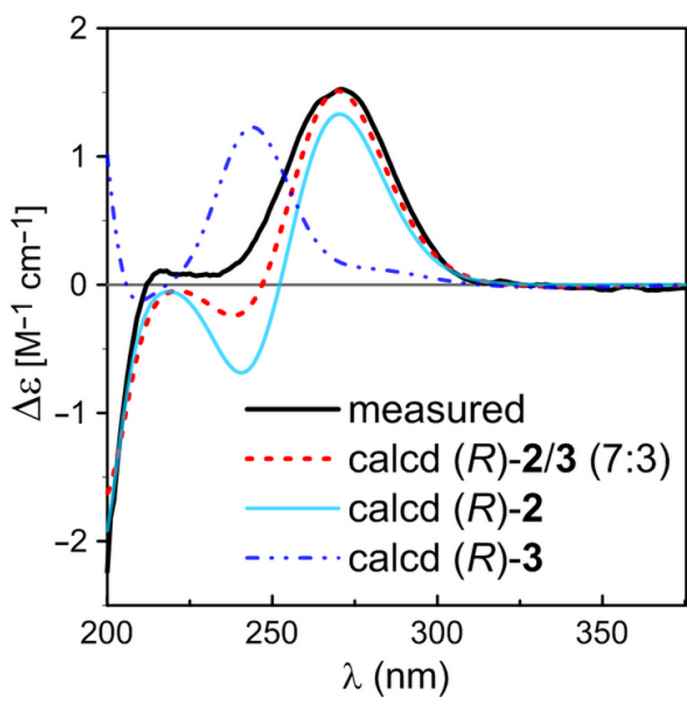

Figure 4: Comparison of the experimental ECD spectrum with the $\mathrm{BH} \& \mathrm{HLYP} / T Z V P$ calculated spectra of the mixture of $(R)-2 / 3(7: 3)$ and individual $(R)-2$ and $(R)-3$ in $\mathrm{MeOH}(\sigma=0.38 \mathrm{eV}$, shift $=+18 \mathrm{~nm}$, scaling factor $=0.44,0.14$, and 0.13 , respectively).

sis every $12 \mathrm{~h}$. As a result, the interconversion between $\mathbf{2}$ and $\mathbf{3}$ was found to occur before $12 \mathrm{~h}$ and reach equilibrium (estimated ratios between $\mathbf{2} / \mathbf{3}$ were 52:48 in $\mathbf{2}$ and 53:47 in $\mathbf{3}$ according to peak area intensities) at $36 \mathrm{~h}$ (Figure 5), whereas no changes were detected for the solutions kept in the dark (Figure 5), confirming the interconversion is a photoinduced geometrical isomerization. 
2 in dark, 36 h, 2/3 = 100:0

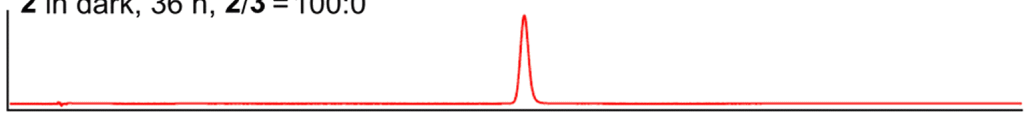

2 under light, 12 h, 2/3=76:24

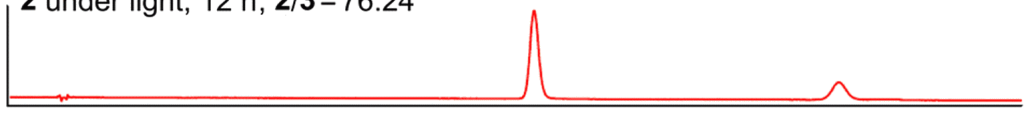

2 under light, 24 h, 2/3 = 60:40

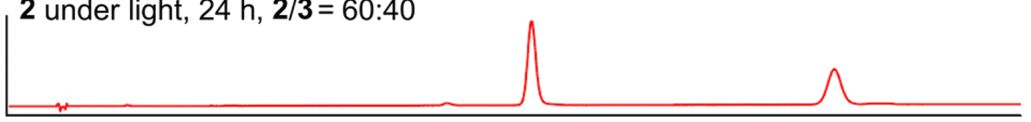

2 under light, 36 h, 2/3 = 52:48

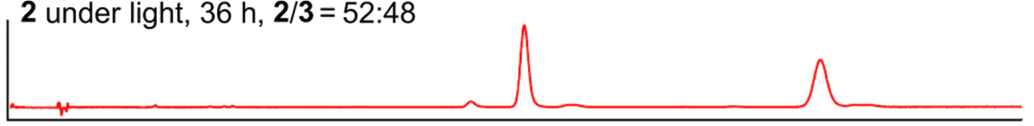

3 under light, 36 h, 2/3=53:47

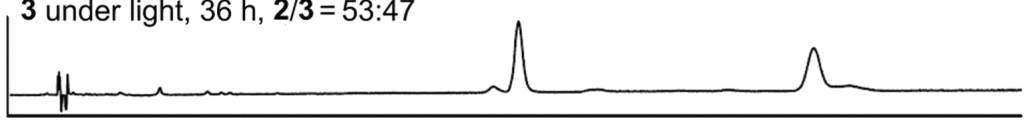

3 under light, 24 h, $\mathbf{2} / \mathbf{3}=45: 55$

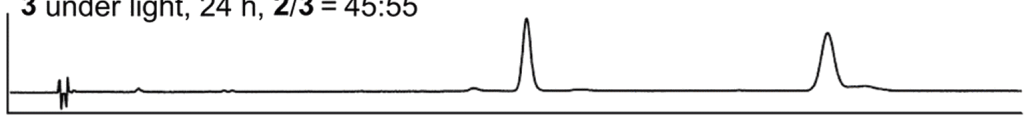

3 under light, 12 h, 2/3 = 28:72
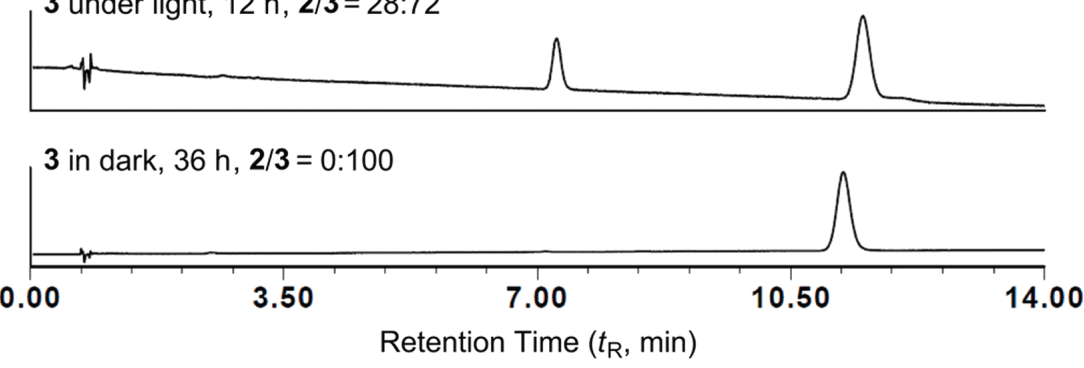

Figure 5: UPLC analysis of photoreaction products of $\mathbf{2}$ (around $t_{\mathrm{R}}=7.5 \mathrm{~min}$ ) and $\mathbf{3}$ (around $t_{\mathrm{R}}=11.5 \mathrm{~min}$ ).

Compounds 2 and 3 possess a chiral 6-ethylidene-2-cyclohexenone chromophore. To the best of our knowledge, $Z / E$ photoisomerizations of compounds with this kind of chromophore had been rarely reported. For better understanding the insights into this reaction, we conducted theoretical investigation using the truncated structures 2a and 3a (Figure 1). At first, the lowest-energy geometries of $\mathbf{2 a}$ and $\mathbf{3 a}$ in $\mathrm{MeOH}$ in the ground $\left(\mathrm{S}_{0}\right)$, first singlet excited $\left(\mathrm{S}_{1}\right)$, and first triplet excited $\left(\mathrm{T}_{1}\right)$ states were optimized at the B3LYP/def2-SVP level. Starting from these energy minima, other equilibrium points rotating around the C6-C $\alpha$ double bond in $\mathrm{S}_{0}, \mathrm{~S}_{1}$, and $\mathrm{T}_{1}$ states were located by relaxed potential energy surface scans, except for geometries around torsion angles $(\mathrm{C} 1-\mathrm{C} 6-\mathrm{C} \alpha-\mathrm{C} \beta, \Phi)$ of $90^{\circ}$ and $-90^{\circ}$ in the $\mathrm{S}_{1}$ surface, for which optimizations failed to converge. Due to the presence of the stereogenic center $\mathrm{C} 4$ in $\mathbf{2 a}$ and $\mathbf{3 a}$, the twisted structures around $\Phi 90^{\circ}$ and $-90^{\circ}$ are diastereomeric in chirality [15]. Thus, two twisted minima, $\mathrm{P}$ and $\mathrm{P}^{\prime}\left(\Phi=77^{\circ}\right.$ and $-84^{\circ}$, respectively) in the $T_{1}$ surface and two energy maxima
( $\Phi=90^{\circ}$ and $-90^{\circ}$, respectively) in $\mathrm{S}_{0}$ surface were located. The resultant potential energy surfaces of the three states and the geometries of key stationary points are shown in Figure 6. The key bond lengths and torsion angles $\Phi$ of these geometries are presented in Table 2. Compound $\mathbf{4}$ has a structure similar to 2 except for replacement of the $\mathrm{C} 2-\mathrm{C} 3$ double bond by a single bond. Its geometrical isomerization was not observed in the present study, but (E)-2-ethylidenecyclohexanone, which has a similar chromophore to that of $\mathbf{4}$, was reported to be able to give the $Z$-isomer upon photoirridiation [16]. For comparison purpose, the truncated structure (4a, Figure 1) of this compound was also calculated using the same methods. The lowestenergy geometries of $(E)$ - and $(Z)-\mathbf{4 a}$ in the $\mathrm{S}_{0}, \mathrm{~S}_{1}\left((E)-\mathbf{4 a}-\mathrm{S}_{1}\right.$, $\left.(Z)-\mathbf{4 a}-\mathrm{S}_{1}\right)$, and $\mathrm{T}_{1}\left(\mathrm{P}-\mathbf{4 a}, \mathrm{P}^{\prime}-\mathbf{4 a}\right)$ surfaces and the two energy maxima $\left((E)-\mathbf{4 a}-\mathrm{T}_{1},(Z)-\mathbf{4 a}-\mathrm{T}_{1}\right)$ in the $\mathrm{T}_{1}$ surface were optimized and their key geometrical parameters are also listed in Table 2. Analysis of geometrical parameters of key points in the excited and ground states (Table 2) showed that the $S_{1}$ and $T_{1}$ 
Table 2: Relative energies and selected geometrical parameters of key stationary points in $S_{0}, S_{1}$, and $T_{1}$ potential energy surfaces of $\mathbf{2 a} / \mathbf{3 a}$ and $\mathbf{4 a}$.

\begin{tabular}{|c|c|c|c|c|c|c|c|c|}
\hline \multirow[b]{2}{*}{ geometry } & \multirow{2}{*}{$\begin{array}{c}\Delta E \\
(\mathrm{kcal} / \mathrm{mol})\end{array}$} & \multicolumn{6}{|c|}{ bond lengths $(\AA)$} & \multirow{2}{*}{$\begin{array}{c}\Phi \\
\text { (degrees) }\end{array}$} \\
\hline & & C1-01 & $\mathrm{C} 1-\mathrm{C} 2$ & C2-C3 & C1-C6 & C6-Ca & $\mathrm{C} \alpha-\mathrm{C} \beta$ & \\
\hline $2 a$ & 0.0 & 1.228 & 1.492 & 1.351 & 1.500 & 1.350 & 1.494 & -179.94 \\
\hline $3 a$ & 1.57 & 1.229 & 1.494 & 1.352 & 1.496 & 1.352 & 1.497 & 0.72 \\
\hline $2 b$ & 75.73 & 1.308 & 1.445 & 1.369 & 1.449 & 1.372 & 1.495 & 176.99 \\
\hline $3 b$ & 74.70 & 1.308 & 1.452 & 1.367 & 1.449 & 1.369 & 1.491 & -0.54 \\
\hline$P$ & 54.85 & 1.250 & 1.491 & 1.347 & 1.452 & 1.466 & 1.498 & 76.78 \\
\hline$P^{\prime}$ & 54.80 & 1.250 & 1.491 & 1.347 & 1.452 & 1.466 & 1.498 & -83.71 \\
\hline 2c & 61.18 & 1.266 & 1.486 & 1.352 & 1.429 & 1.497 & 1.482 & 177.72 \\
\hline $3 c$ & 62.88 & 1.263 & 1.492 & 1.351 & 1.431 & 1.503 & 1.483 & -1.171 \\
\hline$(E)-\mathbf{4 a}$ & 0.0 & 1.222 & 1.532 & 1.536 & 1.505 & 1.351 & 1.494 & -179.95 \\
\hline$(Z)-4 a$ & 1.40 & 1.222 & 1.533 & 1.540 & 1.501 & 1.351 & 1.497 & 1.04 \\
\hline$(E)-4 a-S_{1}$ & 77.06 & 1.291 & 1.552 & 1.530 & 1.410 & 1.400 & 1.494 & 177.96 \\
\hline$(Z)-4 a-S_{1}$ & 76.10 & 1.292 & 1.557 & 1.530 & 1.412 & 1.396 & 1.490 & 1.41 \\
\hline$P-4 a$ & 53.19 & 1.241 & 1.535 & 1.535 & 1.456 & 1.469 & 1.495 & 79.08 \\
\hline$P^{\prime}-4 a$ & 53.19 & 1.241 & 1.535 & 1.535 & 1.456 & 1.469 & 1.495 & 83.24 \\
\hline$(E)-4 a-T_{1}$ & 60.0 & 1.263 & 1.533 & 1.535 & 1.428 & 1.505 & 1.484 & -175.70 \\
\hline$(Z)-4 a-T_{1}$ & 61.0 & 1.254 & 1.539 & 1.533 & 1.436 & 1.505 & 1.486 & 4.30 \\
\hline
\end{tabular}

minima of $\mathbf{2 a} / \mathbf{3}$ a correspond to stable ${ }^{1}\left(\mathrm{n}-\pi^{*}\right)$ and ${ }^{3}\left(\pi-\pi^{*}\right)$ states of $\alpha, \beta$-enones [14], respectively, and the $\mathrm{T}_{1}$ planar maxima, with increased the $\mathrm{C} 1-\mathrm{O} 1$ and $\mathrm{C} 6-\mathrm{C} \alpha$ bond lengths and a decreased $\mathrm{C} 1-\mathrm{C} 6$ bond length relative to those of $\mathrm{T}_{1}$ minima, show similarity to a $T_{2} \pi-\pi^{*}$ species [14]. Comparison of parameters of geometries in excited states between $\mathbf{2 a} / \mathbf{3 a}$ and $4 \mathbf{a}$ revealed that the electron delocalization are extended to $\mathrm{C} 2$ and $\mathrm{C} 3$ in the $\mathrm{S}_{1}$ minima $\mathbf{2 b}$ and $\mathbf{3 b}$ and due to this, their $\mathrm{C} 1-\mathrm{C} 6$ bond length is increased by about $0.04 \AA$ while that of $\mathrm{C} 6-\mathrm{C} \alpha$ is decreased by about $0.03 \AA$ with respect to those in $(E)-\mathbf{4 a}-\mathrm{S}_{1}$ and $(Z)-4 a-S_{1}$ (Table 2), implying that the presence of $C 2-C 3$ double bond in $\mathbf{2 a} / \mathbf{3 a}$ strengthens $\mathrm{C} 6-\mathrm{C} \alpha$ double bond and increases the rotational barrier of $\mathrm{C} 6-\mathrm{C} \alpha$ bond in the $\mathrm{S}_{1}\left(\mathrm{n}-\pi^{*}\right)$ state. In contrast, no significant differences between $\mathbf{2 a / 3 a}$ and 4a can be found in the $T_{1}\left(\pi-\pi^{*}\right)$ states, including the rotational barriers of $\mathrm{C} 6-\mathrm{C} \alpha$ bond (Table 2).

In respect to the photoreaction path, it is predicted that the $Z / E$ isomerization of $\mathbf{2 a / 3 \mathbf { a }}$ is impossible to take place along the $\mathrm{S}_{1}$ surface due to the presence of large rotational barrier $(>25 \mathrm{kcal} / \mathrm{mol})$ in accessing the twisted intermediates (Figure 6). Instead, radiationless relaxations via an intersystem crossing (ISC) from the $S_{1}$ minima $\mathbf{2} \mathbf{b}$ and $\mathbf{3} \mathbf{b}$ to the $T_{1}$ maxima $\mathbf{2 c}$ and $\mathbf{3 c}$, respectively, are energetically and symmetrically reasonable $[14,17]$ as well as are preferred according to El-Sayed's rules [18]. Therefore, the isomerization of $\mathbf{2 a / 3 a}$, after vertical excitation, is proposed to proceed in the route as shown in Figure 6, which involves radiationless decay from the $\mathrm{S}_{1}$ minima to the triplet manifold via an ISC and then from the $\mathrm{T}_{1}$ twisted minima to the ground state via a second ISC, leading to isomerization of the $\mathrm{C} 6-\mathrm{C} \alpha$ double bond. This route is generally similar to those proposed for isomerization of the $\mathrm{C}-\mathrm{C}$ double bond in acyclic $\alpha, \beta$-enones $[14,17]$, but more complicated in details. Due to the presence of two $\mathrm{T}_{1}$ minima and two $\mathrm{S}_{0}$ maxima, there are two equivalent points for the second ISC, one around $\Phi=90^{\circ}$ the other around $\Phi=-90^{\circ}$, and two points being with slightly different energy gaps. Any of these two ISC points is accessible from either $\mathbf{2 c}$ or $\mathbf{3 c}$ and can decay to either 2a or 3a (Figure 6).

With the calculated energies, some observed results in experiments can also be explained. The slightly faster reaction of $\mathbf{3}$ and higher yield of $\mathbf{2}$ in equilibrium shown in Figure 5 are generally in accordance with the difference in energies between $\mathbf{2 a}$ and 3a (Table 2). They may also be related to the energy gaps between $\mathbf{2 b} / \mathbf{2 c}$ and $\mathbf{3 b} / \mathbf{3 c}$ (Figure 6), for which a more efficient ISC is expected for the smaller energy gap $[14,17]$. The weak reactivity of 4 in photoisomerization (not observed in the present study) can be attributable mainly to its higher vertical excitation energy $(87.1 \mathrm{kcal} / \mathrm{mol}$ in $4 \mathbf{a})$ relative to those of 2 $(81.6 \mathrm{kcal} / \mathrm{mol}$ in $\mathbf{2 a})$ and $\mathbf{3}(79.5 \mathrm{kcal} / \mathrm{mol}$ in $\mathbf{3 a})$.

\section{Antifungal activity and cytotoxicity}

Compounds $\mathbf{1}$ and 4-6 and the mixture of $\mathbf{2}$ and $\mathbf{3}$ were evaluated for the in vitro antifungal activity against Colletotrichum gloeosporioides, Phytophthora infestans, and Saccharomyces cerevisiae using a previously described method [19]. The minimum inhibitory concentration (MIC) data were listed 


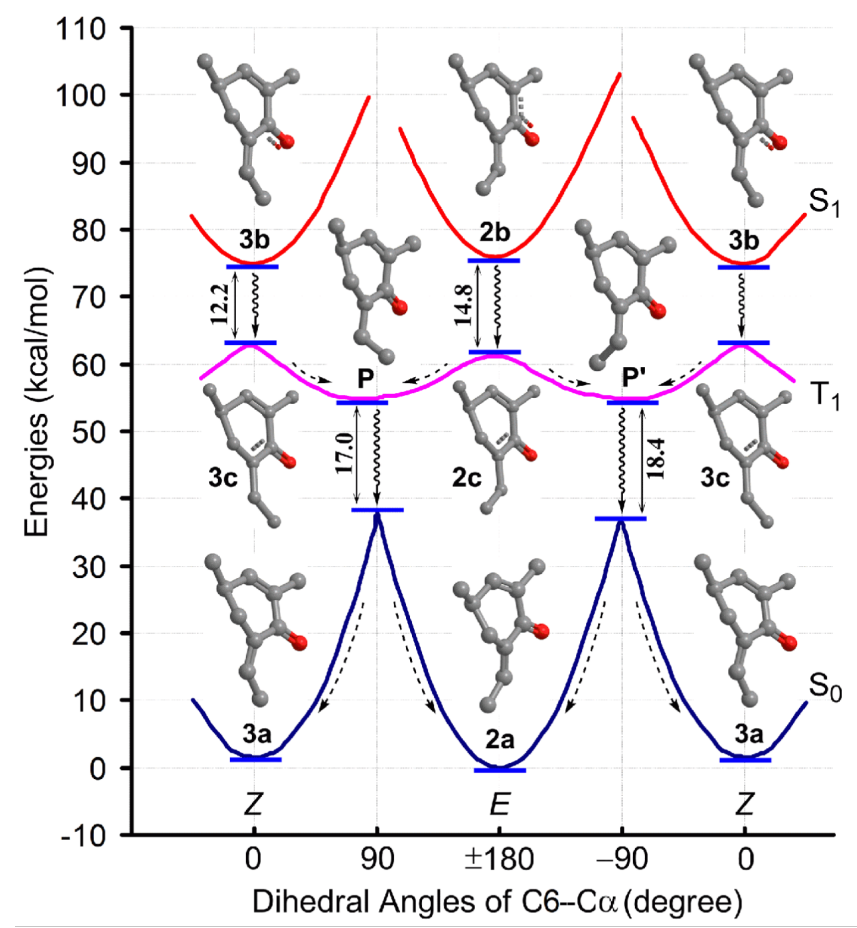

Figure 6: Potential energy surfaces of $2 a / 3 a$ in the $S_{0}, S_{1}$, and $T_{1}$ states, geometries of key points in the surfaces, and proposed photoreaction path (dashed arrow: vibrational relaxation; wavy arrow: ISC; double headed arrow: energy gap between the two points).

in Table 3. Compounds $\mathbf{5}$ and $\mathbf{6}$, as previously reported [20,21], displayed activity against all tested fungal strains and $\mathbf{5}$ showed a superior activity to $\mathbf{6}$, whereas compounds $\mathbf{1}$ and $\mathbf{4}$ and the mixture of $\mathbf{2}$ and $\mathbf{3}$ were found to be inactive (MIC $>100 \mu \mathrm{g} / \mathrm{mL}$ ) against all tested strains, which supported the previous finding that the $\mathrm{OH}-\alpha$ was important to the antifungal activity of cycloheximide derivatives (4 vs 6) [21,22], and suggested that 2,3-dehydrogenation might result in the loss of the activity ( $\mathbf{1}$ vs $\mathbf{5}, \mathbf{6})$. The cytotoxicity of these isolates against human lung epithelial carcinoma (A549), human cervical epithelial adenocarcinoma (HeLa), and human breast carcinoma (MCF-7) was also evaluated, using MTT assay [23] with doxorubicin as a positive control. As shown in Table 3, the isolates showed a similar activity profile with that of the antifungal activity, e.g., only $\mathbf{5}$ and $\mathbf{6}$ were active and others were inactive $(>50 \mu \mathrm{M})$ toward all the tested cell lines. These findings suggested that these cycloheximide derivatives possibly exert the antifungal and cytotoxic activities via a similar mode of action.

\section{Conclusion}

Three new (1-3) and three known (4-6) cycloheximide congeners were obtained from the cultures of Streptomyces sp. SC0581. The structure elucidation of the new compounds were

Table 3: Antifungal activity and cytotoxicity of 1-6

\begin{tabular}{|c|c|c|c|c|c|c|}
\hline \multirow[b]{2}{*}{ compound } & \multicolumn{3}{|c|}{ antifungal activity (MIC, $\mu \mathrm{g} / \mathrm{mL})$} & \multicolumn{3}{|c|}{ cytotoxicity $\left(\mathrm{IC}_{50}, \mu \mathrm{M}\right)^{\mathrm{b}}$} \\
\hline & C. gloeosporioides & P. infestans & S. cerevisiae & A549 & Hela & MCF-7 \\
\hline 5 & 25.0 & 25.0 & 3.1 & $15.8 \pm 3.4$ & $15.6 \pm 3.6$ & $18.1 \pm 0.2$ \\
\hline 6 & 50.0 & 50.0 & 6.3 & $30.0 \pm 3.8$ & $21.9 \pm 2.9$ & $21.9 \pm 2.9$ \\
\hline doxorubicin & & & & $0.12 \pm 0.02$ & $0.31 \pm 0.02$ & $1.00 \pm 0.20$ \\
\hline
\end{tabular}

${ }^{a}$ Compounds 1 and 4 and the mixture of 2 and 3 being inactive against all tested fungi (MIC $\left.>100 \mu \mathrm{g} / \mathrm{mL}\right)$ and tumor cells $\left(\mathrm{IC}_{50}>50 \mu \mathrm{M}\right)$, are not listed. ${ }^{b}$ Values represent means \pm SD based on three individual experiments. 
achieved by spectroscopic analysis in combination with theoretical conformational analysis and ECD simulations, in which theoretical computations were shown to play a key role in solving challenges in assignments of relative and absolute configurations. Analysis of the antifungal and cancer cell toxic activity data of 1-6 suggested that change of the C2-C3 single bond to a double bond can lead to the loss of the activities and supported the OH- $\alpha$ is important to the activities of cycloheximide congeners. Furthermore, compounds $\mathbf{2}$ and $\mathbf{3}$, with a chiral 6-ethylidene-2-cyclohexenone chromophore, were found to undergo $E / Z$ photoisomerization under the indoor light. Theoretical investigation showed the presence of the $\mathrm{C} 2-\mathrm{C} 3$ double bond in $\mathbf{2}$ and $\mathbf{3}$ strengthens the $\mathrm{C} 6-\mathrm{C} \alpha$ double bond and increases the rotational barrier of the $\mathrm{C} 6-\mathrm{C} \alpha$ bond in the $\mathrm{S}_{1}$ $\left(\mathrm{n}-\pi^{*}\right)$ states due to the extended electron delocalization, whereas it scarcely affects the $T_{1}\left(\pi-\pi^{*}\right)$ states, compared to those in 4 . It also revealed a photoisomerization route similar to that commonly found in acyclic $\alpha, \beta$-enones [14,17], except for the presence of two equivalent points (around $\Phi 90^{\circ}$ and $-90^{\circ}$, respectively) for the ISC from $\mathrm{T}_{1}$ to $\mathrm{S}_{0}$ state, arising from the chiral nature of molecules.

\section{Experimental}

\section{General experimental procedures}

Optical rotations were recorded in $\mathrm{MeOH}$ on a Perkin-Elmer 343 spectropolarimeter. UV spectra and ECD spectra were obtained simultaneously on a Chirascan CD spectrometer (Applied Photophysics Ltd., England) using $\mathrm{MeOH}$ as solvent. ${ }^{1} \mathrm{H}$ NMR, ${ }^{13} \mathrm{C}$ NMR, and 2D NMR data were recorded on a Bruker Avance III $500 \mathrm{MHz}$ spectrometer with TMS as internal standard. HRESIMS data were recorded on a Bruker maXis Q-TOF spectrometer. Preparative HPLC were carried out with a Shimadzu Shim-packed Pro-ODS column $(20 \mathrm{~mm} \times 25 \mathrm{~cm})$ equipped with a Shimadzu LC-6AD pump and a Shimadzu RID-10A refractive index detector. UPLC analysis was performed on an Acquity H-Class UPLC system consisting of a quaternary solvent delivery system, an auto-sampler, and a DAD detector. For column chromatography, silica gel 60 (100-200 mesh, Qingdao Marine Chemical Ltd., Qingdao, People's Republic of China), YMC ODS (75 $\mu \mathrm{m}$, YMC Co. Ltd., Kyoto, Japan) and Sephadex LH-20 (GE Healthcare, Uppsala, Sweden) were used. Analytical TLC were performed on HSGF254 silica gel plates $(0.2 \mathrm{~mm}$, Yantai Jiangyou silica gel Development Co. Ltd., Yantai, China); spots were visualized after spraying with $10 \% \mathrm{H}_{2} \mathrm{SO}_{4}$ solution followed by heating.

\section{Biological material}

Streptomyces sp. SC0581, isolated from a soil sample collected from Dinghu Mountain Biosphere Reserve, Guangdong, People's Republic of China, was identified according to mor- phological characteristics and sequence analysis of the ITS region (GenBank accession no. KX687558). A reference strain maintained at $-80{ }^{\circ} \mathrm{C}$ was deposited in the culture collection of South China Botanical Garden, Chinese Academy of Sciences, Guangzhou, People's Republic of China.

\section{Fermentation, extraction and isolation}

The strain was grown on the PDA medium at $28^{\circ} \mathrm{C}$ for 10 days and 6 pieces of PDA culture plugs of the strain were inoculated into each of two $500 \mathrm{~mL}$ Erlenmeyer flasks containing $150 \mathrm{~mL}$ of seed medium (glucose $0.4 \%$, malt extract $1.0 \%$, yeast extract $0.4 \%, \mathrm{pH} 5.5)$ and shaken on a rotatory $(150 \mathrm{rpm})$ at $28{ }^{\circ} \mathrm{C}$ for 2 days. Then, the cultures were transferred into three $3 \mathrm{~L}$ flasks containing $1 \mathrm{~L}$ of seed medium and cultivated at the same culture conditions. Finally, $10 \mathrm{~mL}$ each of the culture broth was transferred into two hundred $500 \mathrm{~mL}$ flasks containing $60 \mathrm{~mL}$ of YMG medium and $60 \mathrm{~g}$ of wheat grains, and the fermentation was carried out stably in the dark at $28{ }^{\circ} \mathrm{C}$ for 40 days. The obtained solid fermentation cultures were extracted with $95 \%$ EtOH for three times and concentrated in vacuum. The resultant extract was successively partitioned between petroleum ether, EtOAc, and $n$-BuOH. The EtOAc and $n$-BuOH soluble fractions, showing the activity against $P$. infestans, were combined and subjected to silica gel column chromatography (CC) eluted with $\mathrm{CHCl}_{3} / \mathrm{MeOH}$ mixtures of increasing polarity (100:0 to 70:30) to give twenty fractions including two antifungal fractions, Fr. $1\left(\mathrm{CHCl}_{3} / \mathrm{MeOH}, 95: 5\right)$ and Fr. $6\left(\mathrm{CHCl}_{3} /\right.$ $\mathrm{MeOH}, 90: 10)$. Fr. 1 (6.0 g) was further separated by ODS CC using aqueous $\mathrm{MeOH}(10-90 \%)$ to obtain five subfractions (Frs. 1A-1E). Fr. 1B (40\% MeOH) was purified by preparative HPLC using isocratic elution of aqueous $\mathrm{CH}_{3} \mathrm{CN}(20 \%)$ at a flow rate of $5 \mathrm{~mL} / \mathrm{min}$ to afford $5\left(9 \mathrm{mg}, t_{\mathrm{R}}=80.4 \mathrm{~min}\right), \mathbf{6}$ ( $5 \mathrm{mg}, t_{\mathrm{R}}=60.0 \mathrm{~min}$ ), and the mixture of $\mathbf{2}$ and $\mathbf{3}(4 \mathrm{mg}, \mathbf{2}$, $\left.t_{\mathrm{R}}=105.5 \mathrm{~min}, \mathbf{3}, t_{\mathrm{R}}=180.2 \mathrm{~min}\right)$. Fr. $1 \mathrm{C}(50 \% \mathrm{MeOH})$ was separated by preparative HPLC using $40 \% \mathrm{MeOH}$ at $5 \mathrm{~mL} / \mathrm{min}$ to yield $4\left(15 \mathrm{mg}, t_{\mathrm{R}}=110.8 \mathrm{~min}\right)$. Fr. 6 (4.4 g) was separated by ODS CC using aqueous $\mathrm{MeOH}(10-90 \%)$ followed by preparative HPLC using $40 \% \mathrm{MeOH}$ at $5 \mathrm{~mL} / \mathrm{min}$ to give 1 $\left(10 \mathrm{mg}, t_{\mathrm{R}}=108.6 \mathrm{~min}\right)$.

2,3-Dehydro-a-epiisocycloheximide (1): Colorless oil; $[\alpha]_{\mathrm{D}}{ }^{25}+1.8(c 0.20, \mathrm{MeOH}) ; \mathrm{UV}(\mathrm{MeOH}) \lambda_{\max }(\log \varepsilon) 201$ (3.40), 237 (3.14); $\mathrm{CD}(\mathrm{MeOH}) \lambda(\Delta \varepsilon) 203$ (-5.06), 237 (+1.62), $344(-0.85) ;{ }^{1} \mathrm{H}$ and ${ }^{13} \mathrm{C}$ NMR data, see Table 1; HRESIMS $(m / z):[\mathrm{M}+\mathrm{Na}]^{+}$calcd for $\mathrm{C}_{15} \mathrm{H}_{21} \mathrm{NNaO}_{4}, 302.1363$; found: 302.1357 .

Mixture of (E)-2,3-dehydroanhydrocycloheximide (2) and (Z)-2,3-dehydroanhydrocycloheximide (3): Colorless oil; $[\alpha]_{\mathrm{D}}{ }^{25}+25.5(c 0.25, \mathrm{MeOH}) ; \mathrm{UV}(\mathrm{MeOH}) \lambda_{\max }(\log \varepsilon) 204$ (4.04), 244 (3.58), 272 (3.49); $\mathrm{CD}(\mathrm{MeOH}) \lambda(\Delta \varepsilon) 271(+1.58)$; 
${ }^{1} \mathrm{H}$ and ${ }^{13} \mathrm{C}$ NMR data, see Table 1 ; HRESIMS $(\mathrm{m} / \mathrm{z})$ : $[\mathrm{M}+\mathrm{Na}]^{+}$calcd for $\mathrm{C}_{15} \mathrm{H}_{19} \mathrm{NNaO}_{3}, 284.1257$; found: 284.1255 .

\section{Evaluation of in vitro antifungal activity}

Saccharomyces cerevisiae, Colletotrichum gloeosporioides, and Phytophthora infestans were used as the test fungal strains. The antifungal activity was evaluated using the microplate Alamar Blue assay (MABA) [19]. For the filamentous fungi, C. gloeosporioides and P. infestans, the strains were grown on PDA cultures for 7 days. The spore suspensions were harvested by flooding the colony with PDB medium, rubbing the surface with a sterile scraper, and filtering with four layers of gauze. The spore suspensions were subjected to quantification with a hemocytometer and adjusted with PDB medium to $1 \times 10^{5} \mathrm{CFU} / \mathrm{mL}$ for the microplate Alamar Blue assay. Test compounds were diluted with the DMSO to give two-fold gradient concentrations. $100 \mu \mathrm{L}$ of spore suspension of each strain containing Alamar Blue $(8 \%, \mathrm{v} / \mathrm{v})$ and the compound solution $(4 \%, v / v)$, was added into 96 -well microtiter plate in triplicate. The final concentrations of tested compounds were $100,50,25,12.5,6.25$ and $3.125 \mu \mathrm{g} / \mathrm{mL}$. To negative control wells were added DMSO instead of the test compound, and blank control wells contained Alamar Blue but without spore suspension. The plate was incubated in the dark at $28{ }^{\circ} \mathrm{C}$ for 6-8 hours. When the color of negative control wells switched from blue to red, the final concentration of the well which was closest to the red one and remained blue was received as the minimal inhibitory concentration (MIC). With regard to the S. cerevisiae, the strain was incubated in PDB medium on a rotary shaker at $150 \mathrm{rpm}$ in $28^{\circ} \mathrm{C}$ for 12 hours. The suspensions of the strain were quantified with a hemocytometer and adjusted with PDB medium to $1 \times 10^{4} \mathrm{CFU} / \mathrm{mL}$. The next steps of microplate Alamar Blue assay for $S$. cerevisiae were the same as mentioned above for the two filamentous fungi.

\section{Evaluation of tumor cell toxicity}

The evaluation was conducted as previously described [23].

\section{Photoinduced interconversion between 2 and 3}

The mixture of $\mathbf{2}$ and $\mathbf{3}$ (7:3) was separated by a SPOLAR C18 column $(4.6 \times 250 \mathrm{~mm}, 5 \mu \mathrm{m})$ using $35 \% \mathrm{MeOH}$ at a flow rate of $1 \mathrm{~mL} / \mathrm{min}$, yielding compounds $2\left(t_{\mathrm{R}}=19.3 \mathrm{~min}\right)$ and 3 $\left(t_{\mathrm{R}}=28.5 \mathrm{~min}\right)$ in pure form. The whole separation process was performed in the dark. Then, two aliquots of $\mathrm{MeOH}$ solutions were prepared for each of $\mathbf{2}$ and $\mathbf{3}$. One aliquot of solution was placed under the natural indoor light (illumination ranging between 155-315 lux) at room temperature and the other was kept in the dark. The two aliquots of solutions were subjected to UPLC analysis every 12 hours on an Acquity UPLC BEH C18 column $(2.1 \times 100 \mathrm{~mm}, 1.7 \mu \mathrm{m})$ using $35 \% \mathrm{MeOH}$ as mobile phase at a flow rate of $0.3 \mathrm{~mL} / \mathrm{min}$. The column temperature was controlled at $40{ }^{\circ} \mathrm{C}$ and detection wavelength was set at $280 \mathrm{~nm}$.

\section{Computational details}

Molecular Merck force field (MMFF) calculations were done using the Spartan'14 program (Wavefunction Inc., Irvine, CA, USA). Density functional theory (DFT) and time-dependent density functional theory (TDDFT) calculations were performed with the Gaussian 09 program package [24]. For computations of ECD spectra, the conformers generated by a MMFF conformational search in an energy window of $10 \mathrm{kcal} / \mathrm{mol}$ were subjected to geometry optimization using the dispersion-corrected DFT-D3 method [25] at the B3LYP-D3/6$31 \mathrm{G}(\mathrm{d})$ level. Frequency calculations were carried out on those optimized conformers with relative energies $(\Delta E)$ less than $4.5 \mathrm{kcal} / \mathrm{mol}$ using the same level to verify that they were true minima and to estimate their relative thermal free energies $(\Delta G)$ at $298.15 \mathrm{~K}$. The more accurate energies of these conformers in $\mathrm{MeOH}$ were obtained with the B3LYP-D3/def2-TZVP method. Solvent effects were taken into account by using polarizable continuum model (PCM). The TDDFT calculations were performed using the hybrid BHandHLYP [26], M11 [27], and/or PBE1PBE [28,29] functionals, and Ahlrichs' basis set TZVP (triple zeta valence plus) polarization [30]. The number of excited states per each molecule was 24 . The ECD spectra were generated by the program SpecDis [31] using a Gaussian band shape from dipole-length dipolar and rotational strengths. Equilibrium population of each conformer at $298.15 \mathrm{~K}$ was calculated from its relative free energies using Boltzmann statistics. The calculated spectra were generated from the low-energy conformers according to the Boltzmann weighting of each conformer in $\mathrm{MeOH}$ solution.

For theoretical investigations on the photoinduced interconversion between $\mathbf{2}$ and $\mathbf{3}$, the truncated structures $\mathbf{2 a}$ and $\mathbf{3 a}$ (Figure 1) were used. Geometries of 2a and 3a in $\mathrm{MeOH}$ solution in $\mathrm{S}_{0}, \mathrm{~S}_{1}$, and $\mathrm{T}_{1}$ states were optimized by DFT (for $\mathrm{S}_{0}$ and $\mathrm{T}_{1}$ ) or TDDFT (for $\mathrm{S}_{1}$ only) calculations at the B3LYP/def2SVP level. For diradical triplets, the spin-unrestricted formalism was used. Solvent effects were treated using PCM. To build $3 \mathrm{D}$ conformers of $\mathbf{2 a}$ and $\mathbf{3 a}$, the global energy minima of $\mathbf{2}$ and 3, obtained in above ECD computations, were used and their glutarimide ring was replaced by a hydrogen atom. The built conformers were subjected to geometry optimizations to obtain the absolute energy minima of $\mathbf{2} \mathbf{a}$ and $\mathbf{3 a}$ in the $\mathrm{S}_{0}, \mathrm{~S}_{1}$, and $T_{1}$ states. Starting from these minima, other equilibrium points rotating around the $\mathrm{C} 6-\mathrm{C} \alpha$ double bond in surfaces of the three states were located by relaxed potential energy surface scans, except for those around $\Phi 90^{\circ}$ and $-90^{\circ}$ in the $S_{1}$ surface, 
for which optimizations failed to converge. Frequency calculations were also carried out on the significant points, including geometries $\mathbf{2 a}-\mathbf{2 c}, \mathbf{3 a}-\mathbf{3 c}, \mathrm{P}$, and $\mathrm{P}^{\prime}$ and verified that they were either true minima or maxima (2c and $\mathbf{3 c}$ only). Structures $(E)$ and $(Z)-\mathbf{4 a}$ were calculated with the same method and their stable energy minima in the $\mathrm{S}_{0}, \mathrm{~S}_{1}$, and $\mathrm{T}_{1}$ states and $\mathrm{T}_{1}$ maxima were optimized (Table 2).

\section{Supporting Information}

\section{Supporting Information File 1}

HRESIMS, 1D and 2D NMR spectra of compounds 1-3; energies, populations, and key torsion angles of low-energy conformers of compounds $\mathbf{1}-\mathbf{3}$ by theoretical computations. [http://www.beilstein-journals.org/bjoc/content/ supplementary/1860-5397-13-103-S1.pdf]

\section{Acknowledgements}

We thank Mr. Yunfei Yuan, South China Botanical Garden, Chinese Academy of Sciences, for NMR spectroscopic measurements, and Ms. Aijun Sun, South China Sea Institute of Oceanology, Chinese Academy of Sciences, for HRESIMS measurements. We gratefully acknowledge support from the Guangzhou Branch of the Supercomputing Center of Chinese Academy of Sciences. This study was supported by an NSFC grant (No. 81172942) and a research project from the Bureau of Science and Technology of Guangzhou Municipality (grant no. 201510010015).

\section{References}

1. Ennis, H. L.; Lubin, M. Science 1964, 146, 1474-1476. doi:10.1126/science.146.3650.1474

2. Obrig, T. G.; Culp, W. J.; McKeehan, W. L.; Hardesty, B. J. Biol. Chem. 1971, 246, 174-181.

3. Schneider-Poetsch, T.; Ju, J.; Eyler, D. E.; Dang, Y.; Bhat, S.; Merrick, W. C.; Green, R.; Shen, B.; Liu, J. O. Nat. Chem. Biol. 2010, 6, 209-217. doi:10.1038/nchembio.304

4. Nakae, K.; Yoshimoto, Y.; Sawa, T.; Homma, Y.; Hamada, M.; Takeuch, T.; Imoto, M. J. Antibiot. 2000, 53, 1130-1136. doi:10.7164/antibiotics.53.1130

5. Saito, N.; Suzuki, F.; Sasaki, K.; Ishida, N. Antimicrob. Agents Chemother. 1976, 10, 14-19. doi:10.1128/AAC.10.1.14

6. Guo, H.-f.; Li, Y.-h.; Yi, H.; Zhang, T.; Wang, S.-q.; Tao, P.-Z.; Li, Z.-r. J. Antibiot. 2009, 62, 639-642. doi:10.1038/ja.2009.87

7. Lawana, V.; Korrapati, M. C.; Mehendale, H. M. Cycloheximide. In Encyclopedia of Toxicology, 3rd ed.; Wexler, P., Ed.; Academic Press: Oxford, 2014; pp 1103-1105. doi:10.1016/B978-0-12-386454-3.00298-0

8. Xue, J.; Wu, P.; Xu, L.; Wei, X. Org. Lett. 2014, 16, 1518-1521. doi:10.1021/ol500418f

9. Wu, P.; Xue, J.; Yao, L.; Xu, L.; Li, H.; Wei, X. Org. Lett. 2015, 17, 4922-4925. doi:10.1021/acs.orglett.5b02536
10. Jeffs, P. W.; McWilliams, D. J. Am. Chem. Soc. 1981, 103, 6185-6192. doi:10.1021/ja00410a034

11. Yang, D.; Xu, Q. Y.; Deng, X. M.; Song, S. Y.; Hu, Z. Y.; Zheng, Z. H. Rec. Nat. Prod. 2015, 9, 336-341.

12. Liu, R. S. H.; Hammond, G. S. Proc. Natl. Acad. Sci. U. S. A. 2000, 97, 11153-11158. doi:10.1073/pnas.210323197

13. Tsuno, T.; Yoshida, M.; Iwata, T.; Sugiyama, K. Tetrahedron 2002, 58, 7681-7689. doi:10.1016/S0040-4020(02)00856-6

14. Reguero, M.; Olivucci, M.; Bernardi, F.; Robb, M. A. J. Am. Chem. Soc. 1994, 116, 2103-2114. doi:10.1021/ja00084a056

15. García-Expósito, E.; González-Moreno, R.; Martín-Vilà, M.; Muray, E.; Rifé, J.; Bourdelande, J. L.; Branchadell, V.; Ortuño, R. M. J. Org. Chem. 2000, 65, 6958-6965. doi:10.1021/jo000549g

16. Schneider, R. A.; Meinwald, J. J. Am. Chem. Soc. 1967, 89, 2023-2032. doi:10.1021/ja00985a011

17. Marian, C. M. Wiley Interdiscip. Rev.: Comput. Mol. Sci. 2012, 2, 187-203. doi:10.1002/wcms.83

18. El-Sayed, M. A. J. Chem. Phys. 1963, 38, 2834-2838. doi:10.1063/1.1733610

19. Cox, K. D.; Quello, K.; Deford, R. J.; Beckerman, J. L. Plant Dis. 2009, 93, 328-331. doi:10.1094/pdis-93-4-0328

20. Wang, J.; He, W.; Huang, X.; Tian, X.; Liao, S.; Yang, B.; Wang, F.; Zhou, X.; Liu, Y. J. Agric. Food Chem. 2016, 64, 2910-2916. doi:10.1021/acs.jafc.6b00527

21. Huang, S.-X.; Yu, Z.; Robert, F.; Zhao, L.-X.; Jiang, Y.; Duan, Y.; Pelletier, J.; Shen, B. J. Antibiot. 2011, 64, 163-166. doi:10.1038/ja.2010.150

22. Ennis, H. L. Biochem. Pharmacol. 1968, 17, 1197-1206. doi:10.1016/0006-2952(68)90056-7

23. Shi, J.-F.; Wu, P.; Jiang, Z.-H.; Wei, X.-Y. Eur. J. Med. Chem. 2014, 71, 219-228. doi:10.1016/j.ejmech.2013.11.012

24. Gaussian 09, revision C.01; Gaussian, Inc.: Wallingford CT, 2010.

25. Grimme, S.; Antony, J.; Ehrlich, S.; Krieg, H. J. Chem. Phys. 2010, 132, 154104. doi:10.1063/1.3382344

26. Gaussian 92/DFT, Revision F.2 ed.; Gaussian, Inc.: Pittsburgh PA, 1993.

27. Peverati, R.; Truhlar, D. G. J. Phys. Chem. Lett. 2011, 2, 2810-2817. doi:10.1021/jz201170d

28. Perdew, J. P.; Burke, K.; Ernzerhof, M. Phys. Rev. Lett. 1996, 77, 3865-3868. doi:10.1103/PhysRevLett.77.3865

29. Adamo, C.; Barone, V. J. Chem. Phys. 1999, 110, 6158-6169. doi:10.1063/1.478522

30. Schäfer, A.; Huber, C.; Ahlrichs, R. J. Chem. Phys. 1994, 100, 5829-5835. doi:10.1063/1.467146

31. Bruhn, T.; Schaumlöffel, A.; Hemberger, Y.; Bringmann, G. Chirality 2013, 25, 243-249. doi:10.1002/chir.22138 


\section{License and Terms}

This is an Open Access article under the terms of the Creative Commons Attribution License

(http://creativecommons.org/licenses/by/4.0), which permits unrestricted use, distribution, and reproduction in any medium, provided the original work is properly cited.

The license is subject to the Beilstein Journal of Organic Chemistry terms and conditions:

(http://www.beilstein-journals.org/bjoc)

The definitive version of this article is the electronic one which can be found at:

doi:10.3762/bjoc. 13.103 